\title{
The Impact of Different Writing Tasks on Intermediate EFL Learners' Writing Performance
}

\author{
Abdolreza Abdali \\ Islamic Azad University, Roudehen Branch, Tehran, Iran \\ Hamidreza Fatemipour \\ Islamic Azad University, Roudehen Branch, Tehran, Iran
}

\begin{abstract}
It is academically believed that conventional methods of teaching writing could not provide satisfactorily the Iranian intermediate English as Foreign Language (EFL) learners with being fully equipped to meet the demand of their authorities while preparing their reports, compositions, essays, papers, assignments, and projects. Therefore, to introduce a desirable approach to teaching writing, researchers usually introduce task based approaches to compensate for such flaws and end such kinds of concerns. So this experimental study tried to investigate the impact of four different pedagogic writing tasks, i.e., Topic Writing (TW), Summary Writing (SW), Graphic Writing (GW), and Picture Writing (PW) on complexity and accuracy of writing performance of aforementioned learners. To this end, 120 subjects were selected as the participants of this experimental study to see which kinds of writing task can ameliorate the current condition well. For implementation the command of the study, altogether 960 written texts as documents of the pre and post test and also treatment were collected and analyzed to pinpoint meticulously the efficacy of these different kinds of writing tasks on subjects' accomplishment in their written production. The results of the study revealed the superiority of SW group for complexity and GW for accuracy of their written productions.
\end{abstract}

Index Terms-Topic Writing (TW), Summary Writing (SW), Graphic Writing (GW), and Picture Writing (PW)

\section{INTRODUCTION}

Writing is an important skill that foreign language learners should develop while learning any language. EFL learners should write reports, thesis, essays, and compositions so as to meet the demands of their authorities. Reviewing the literature of writing, we observe how different researchers confirm that writing has a pivotal function in the daily lives of people. According to Kim and Kim (2005), "writing today has become very important in the daily lives of much of the world's population" (as cited in Marashi \& Dadari, 2012, p. 2500). Also, in a report on writing in America's schools and colleges by Magrath, Ackerman, Branch, and Bristow (2003) known worldwide as the College Board's National Commission, it is observed how the authors underscored the importance of writing. Stating that "writing is not a frill for the few, but an essential skill for the many" (p. 11), the Commission's report highlighted the central role that writing plays for these learners today.

In spite of this importance, as writing is a challenging endeavor, learning and teaching it, is usually postponed to later stages of development at the expense of learning and teaching other three macro skills of language. To compound the problem, it is believed that inappropriateness and inefficacy of conventional approaches to teaching writing is considered as one of the important factors which lead to this undesirable state of writing of EFL learners. Therefore, it is proposed that replacing conventional approaches by task based approaches to teaching writing can improve the current weak quality of writings of these learners. Thus, the need for task based courses arose from the failure of previous approaches to language teaching.

Nowadays, Task Based Language Teaching (TBLT) is considered as an effective approach that has the potential to improve learners' complexity and accuracy of their writings. Nunan (2004) claims that "the ability to use a second language would develop automatically if learners focused on meaning in the process of completing tasks" (p. 9). Therefore, it is believed that a good way to promote effective learning is the time when students are fully engaged in practicing a language task, rather than just learning about the language.

TBLT is considered as one of the latest trends whereby the learners are exposed to authentic, meaning based, and natural language for acquisition. Nunan (2004) believes that task-based learning exploits the metamorphosis process and allows the learners to grow into the language (p. 30). As a paradigm of TBLT, language is used as a tool for completing tasks rather than as a subject in its own right. Therefore, language is regarded as means to do the task rather than as an end.

In task based classes which are heavily influenced by the communicative approach, students freely exchange information and use language without any illogical concern for mistakes. In these classes, learners subconsciously learn the language while performing any kinds of tasks; consequently, any language learning will be incidental. Due to these 
mentioned reasons, some teachers of writing consider this approach as a very interesting and significant practice for teaching.

The researchers in this study regarded task based approach as a promising approach for the facilitation of L2 writing and thus the development of writing skill at intermediate level in an Iranian context. Hence, in line with Chen and Wu (2001), and Pourdana, Karimi Behbahani, and Safdari (2010) they develop this consideration that different kinds of tasks impact on the writing performance of EFL learners differently. Thereafter, to verify this hypothesis, they tried to probe which writing task have significant different impact on accuracy and complexity performance of Iranian intermediate EFL learners' writing.

\section{Methodology}

Materials and Methods: Samuda and Bygate (2008) believe that teachers might consider the best way to arrange activities "to motivate, channel and support learners' efforts to learn" (p. 75). Therefore, concerning this claim, the researchers in this study tried to manipulate the materials and procedure in such a way that well be exploited for improving the writing performance of EFL learners.

To homogenize the proficiency level of 120 participants of the study out of a total of 250 male and female Iranian EFL learners studying English in Payam-e-Nour University in Khoramabad, Lorestan Province in Iran, they were asked to take part in Nelson English Language Tests 300A by (Fowler and Coe, 1976, pp. 38-41). Thereafter, the qualified participants were randomly divided into four homogeneous experimental groups and were asked to write an essay on a similar specified subject as their pre test to get two marks for accuracy and complexity of their writings before any treatments. After 6 sessions of treatment, they were asked to write another essay on a coordinated similar subject as their post test to observe whether different writing tasks impact the accuracy and complexity of writings of these EFL learners differently. It is worth mentioning that their assignments have been corrected by two experienced raters based on Weir, 1990 analytic writing descriptors (as cited in Duddly - Eavens \& St John, 2005, pp. 220-221). Moreover, the students in these writing classes received written and oral feedback for the grammatical, lexical and discourse mistakes in their writings from the raters and teacher. At last, utilizing SPSS, the data were analyzed to promulgate which writing task has superior impact on accuracy and complexity of writing of these learners.

\section{RESULTS AND ANALYSIS}

Field (2009) believes that four assumptions should be met before one decides to run parametric tests: 1) the data should be measured on an interval scale; 2) the subjects should be independent that is to say their performance on the test is not affected by the by performance of other students, 3) the data should enjoy normal distribution and 4) the groups should have homogeneous variances (p. 133). The present data are measured on an interval scale and the subjects perform independently on the tests. The assumption of normality is also met. As displayed in Table 1, the ratios of skewness and kurtosis over their respective standard errors are within the ranges of +/- 1.96(ibid, p. 216).

TABLE 1

NORMALITY TESTS

\begin{tabular}{|c|c|c|c|c|c|c|c|c|}
\hline \multirow[t]{2}{*}{ Group } & & \multirow{2}{*}{$\frac{\mathrm{N}}{\text { Statistic }}$} & \multicolumn{3}{|l|}{ Skewness } & \multicolumn{3}{|l|}{ Kurtosis } \\
\hline & & & Statistic & Std. Error & Ratio & Statistic & Std. Error & Ratio \\
\hline \multirow{5}{*}{ Graphic Writing } & NELSON & 30 & .326 & .427 & 0.763 & -.524 & .833 & -0.629 \\
\hline & PreAccuracy & 30 & .136 & .427 & 0.319 & -.487 & .833 & -0.585 \\
\hline & PostAccuracy & 30 & -.611 & .427 & -1.431 & -.792 & .833 & -0.951 \\
\hline & PreComplexity & 30 & .484 & .427 & 1.133 & .047 & .833 & 0.056 \\
\hline & PostComplexity & 30 & -.700 & .427 & -1.639 & .536 & .833 & 0.643 \\
\hline \multirow{5}{*}{ Picture Writing } & NELSON & 30 & .566 & .427 & 1.326 & -.314 & .833 & -0.377 \\
\hline & PreAccuracy & 30 & -.249 & .427 & -0.583 & .296 & .833 & 0.355 \\
\hline & PostAccuracy & 30 & .628 & .427 & 1.471 & .238 & .833 & 0.286 \\
\hline & PreComplexity & 30 & -.182 & .427 & -0.426 & -.633 & .833 & -0.760 \\
\hline & PostComplexity & 30 & -.123 & .427 & -0.288 & -1.025 & .833 & -1.230 \\
\hline \multirow{5}{*}{ Summary Writing } & NELSON & 30 & .615 & .427 & 1.440 & -.819 & .833 & -0.983 \\
\hline & PreAccuracy & 30 & -.388 & .427 & -0.909 & -.661 & .833 & -0.794 \\
\hline & PostAccuracy & 30 & -.317 & .427 & -0.742 & -.294 & .833 & -0.353 \\
\hline & PreComplexity & 30 & -.259 & .427 & -0.607 & -1.174 & .833 & -1.409 \\
\hline & PostComplexity & 30 & .393 & .427 & 0.920 & -.830 & .833 & -0.996 \\
\hline \multirow{5}{*}{ Topic Writing } & NELSON & 30 & .521 & .427 & 1.220 & -.141 & .833 & -0.169 \\
\hline & PreAccuracy & 30 & .173 & .427 & 0.405 & -.879 & .833 & -1.055 \\
\hline & PostAccuracy & 30 & .611 & .427 & 1.431 & -.792 & .833 & -0.951 \\
\hline & PreComplexity & 30 & .497 & .427 & 1.164 & .319 & .833 & 0.383 \\
\hline & PostComplexity & 30 & .480 & .427 & 1.124 & -.513 & .833 & -0.616 \\
\hline
\end{tabular}

By the same token, a one-way ANOVA was run to compare the means of the Graphic, Picture, Summary and Topic writing groups on the Nelson test in order to prove that the participants enjoyed the same level of general language 
proficiency prior to the main study. As displayed in Table 2, the Levene's F-value of 2.20 is not significant ( $\boldsymbol{\rho}$ $=.091>.05)$. This represents that the four groups enjoy homogenous variances on the Nelson.

TABLE 2

LEVENE'S TEST OF HOMOGENEITY OF VARIANCES; NELSON TEST

\begin{tabular}{lccc}
\hline Levene Statistic & df1 & df2 & Sig. \\
\hline 2.206 & 3 & 116 & .091 \\
\hline
\end{tabular}

As you see the variance is not significantly different, (i.e. they are similar and the homogeneity of variance assumption is tenable).

Moreover, another one-way ANOVA was run to compare the means of the Graphic, Picture, Summary and Topic writing groups on the Pretest of Writing Accuracy in order to prove that they enjoyed the same level of writing accuracy prior to the main study. As displayed in Table 3, the Levene's F-value of 1.32 is not significant $(\rho=.270>.05)$. Thus, one can infer that the four groups enjoy homogenous variances on the Pretest of Writing Accuracy.

TABLE 3

LEVENE's TEST OF HOMOGENEITY OF VARIANCES; PRETEST OF WRITING ACCURACY

\begin{tabular}{llll}
\hline Levene Statistic & df1 & df2 & Sig. \\
\hline 1.325 & 3 & 116 & .270 \\
\hline
\end{tabular}

By the same token, based on the results displayed in Table $4\left(\mathrm{~F}(3,116)=1.77, \rho=.156>.05 ; \omega^{2}=.019\right.$ it represents a weak effect size), it can be concluded that there were not any significant differences between means of the four groups on the Pretest of Writing Accuracy. Thus, it can be claimed that they enjoyed the same level of writing accuracy prior to the main study.

TABLE 4

ONE-WAY ANOVA PRETEST OF WRITING ACCURACY BY GROUPS

\begin{tabular}{llllll}
\hline \multicolumn{6}{c}{ ONE-WAY ANOVA PRETEST OF WRITING ACCURACY BY GROUPS } \\
\hline Between Groups & Sum of Squares & Df & Mean Square & F & Sig. \\
\hline Within Groups & 12.092 & 3 & 4.031 & 1.772 & .156 \\
\hline Total & 263.833 & 116 & 2.274 & & \\
\hline
\end{tabular}

Another one-way ANOVA was run to compare the means of the Graphic, Picture, Summary and Topic writing groups on the Pretest of Writing Complexity in order to prove that they enjoyed the same level of writing complexity prior to the main study. As displayed in Table 5, the Levene's F-value of 2.25 is not significant $(\rho=.086>.05)$. Thus, based on the findings of ANOVA, researchers of the study claim that the four groups enjoy homogenous variances on the Pretest of Writing Complexity.

TABLE 5

LEVENE'S TEST OF HOMOGENEITY OF VARIANCES; PRETEST OF WRITING COMPLEXITY

\begin{tabular}{llll}
\hline Levene Statistic & df1 & df2 & Sig. \\
\hline 2.251 & 3 & 116 & .086 \\
\hline
\end{tabular}

Moreover, based on the results displayed in Table $6\left(\mathrm{~F}(3,116)=.541, \rho=.655>.05 ; \omega^{2}=.012\right.$ it represents a weak effect size), it can be concluded that there were not any significant differences between means of the four groups on the Pretest of Writing Complexity. Thus, it can be claimed that they enjoyed the same level of writing complexity prior to the main study.

TABLE 6

ONE-WAY ANOVA PRETEST OF WRITING COMPLEXITY BY GROUPS

\begin{tabular}{llllll}
\hline \multicolumn{7}{c}{ ONE-WAY ANOVA PRETEST OF WRITING COMPLEXITY BY GROUPS } \\
\hline Setween Groups & 3.267 & Df & Mean Square & F & Sig. \\
\hline Within Groups & 233.533 & 3 & 1.089 & .541 & .655 \\
\hline Total & 236.800 & 116 & 2.013 & & \\
\hline
\end{tabular}

Before discussing the one-way ANOVA results it is worth mentioning that the four groups enjoy homogenous variances on the Posttest of Writing Accuracy. As displayed in Table 7, the Levene's F-value of 1.70 is not significant $(\boldsymbol{\rho}=.171>.05)$. Thus, the results of the one-way ANOVA can be reported.

TABLE 7

\begin{tabular}{|c|c|c|c|}
\hline Levene Statistic & df1 & df 2 & Sig. \\
\hline 1.700 & 3 & 116 & .171 \\
\hline
\end{tabular}

Also, the findings of one-way ANOVA reveal that the four groups enjoy homogenous variances on the Posttest of Writing Complexity. As displayed in Table 8, the Levene's F-value of 2.14 is not significant $(\rho=.099>.05)$. Thus, the four groups enjoyed the same level of homogeneity of variances after treatment. 
TABLE 8

LEVENE'S TEST OF HOMOGENEITY OF VARIANCES; POSTTEST OF WRITING COMPLEXITY

\begin{tabular}{llll}
\hline Levene Statistic & df1 & df2 & Sig. \\
\hline 2.141 & 3 & 116 & .099 \\
\hline
\end{tabular}

However, after treatment the researchers investigate the value of significant difference of performance of these learners after treatment. They wanted to probe whether different kinds of tasks have different impacts on writing performance of these EFL learners; and whether while comparing and contrasting them, the findings of ANOVA show any significant difference in their writing performance. In order to carry out further analysis, the researchers managed One-Way ANOVA Posttest of Writing Accuracy and Complexity by Groups, and also Post-Hoc Scheffe's Tests to find out which groups differ.

Based on the results displayed in Table $9\left(\mathrm{~F}(3,116)=5.89, \rho=.001<.05 ; \omega^{2}=.109\right.$ it represents an almost large effect size) it can be concluded that there were significant differences between means of the four groups on the Posttest of Writing Accuracy. Thus, it can be claimed that types of writing tasks have significant effect on accuracy of writing performance of Iranian intermediate EFL learners.

TABLE 9

ONE-WAY ANOVA POSTTEST OF WRITING ACCURACY BY GROUPS

\begin{tabular}{llllll}
\hline & Sum of Squares & Df & Mean Square & F & Sig. \\
\hline Between Groups & 22.025 & 3 & 7.342 & 5.891 & .001 \\
\hline Within Groups & 144.567 & 116 & 1.246 & & \\
\hline Total & 166.592 & 119 & & & \\
\hline
\end{tabular}

Based on the results displayed in Table $10\left(\mathrm{~F}(3,116)=11.7, \rho=.000<.05 ; \omega^{2}=.215\right.$ it represents a large effect size $)$ it can be concluded that there were significant differences between means of the four groups on the Posttest of Writing Complexity. Thus, it can be claimed that types of writing tasks have significant effect on complexity of writing performance of Iranian intermediate EFL learners.

TABLE 10

ONE-WAY ANOVA POSTTEST OF WRITING COMPLEXITY BY GROUPS

\begin{tabular}{llllll}
\hline & Sum of Squares & Df & Mean Square & F & Sig. \\
\hline Between Groups & 64.092 & 3 & 21.364 & 11.978 & .000 \\
\hline Within Groups & 206.900 & 116 & 1.784 & & \\
\hline Total & 270.992 & 119 & & & \\
\hline
\end{tabular}

Although the these F-values indicates significant differences between the means of the four groups on the posttest of accuracy and complexity, the researchers managed the post-hoc Scheffe's tests so as to compare the significant difference of these EFL learners' performance. During the following discussion of the post-hoc tests; "M" and "MD" stand for "mean" and "mean difference" respectively.

TABLE 11

POST-HOC SCHEFFE'S TESTS; POSTTEST OF WRITING ACCURACY BY GROUPS

\begin{tabular}{|c|c|c|c|c|c|}
\hline \multirow[t]{2}{*}{ (I) Group } & \multirow[t]{2}{*}{ (J) Group } & \multirow{2}{*}{$\begin{array}{l}\text { Mean } \\
\text { Difference (I-J) }\end{array}$} & \multirow{2}{*}{ Std. Error } & \multicolumn{2}{|c|}{ Sig. 95\% Confidence Interval } \\
\hline & & & & Lower Bound & Upper Bound \\
\hline \multirow{3}{*}{ Graphic Writing } & Picture Writing & $.933^{*}$ & .288 & .018 .12 & 1.75 \\
\hline & Summary Writing & .633 & .288 & $.191-.18$ & 1.45 \\
\hline & Topic Writing & $1.133^{*}$ & .288 & .002 .32 & 1.95 \\
\hline Picture Writing & Topic Writing & .300 & .288 & $.781-.52$ & 1.12 \\
\hline \multirow{2}{*}{ Summary Writing } & Picture Writing & .200 & .288 & $.923-.62$ & 1.02 \\
\hline & Topic Writing & .500 & .288 & $.394-.32$ & 1.32 \\
\hline
\end{tabular}

1: There was a significant difference between the Graphic Writing $(M=17.07)$ and Picture Writing $(M=16.13)$ groups on the posttest of writing accuracy $(\mathrm{MD}=.933, \rho=.018<.05)$. Thus, there is significant difference between the accuracy of Graphic Writing and Picture Writing tasks.

2: There was not any significant difference between the Graphic Writing $(M=17.07)$ and Summary Writing $(M=$ 16.43) groups on the posttest of writing accuracy $(\mathrm{MD}=.633, \rho=.191>.05)$. Thus, there is not any significant difference between the accuracy of Graphic Writing and Summary Writing tasks.

3: There was a significant difference between the Graphic Writing $(\mathrm{M}=17.07)$ and Topic Writing $(\mathrm{M}=15.93)$ groups on the posttest of writing accuracy $(\mathrm{MD}=1.13, \rho=.002<.05)$. Thus, there is significant difference between the accuracy Graphic Writing and Topic Writing tasks.

4: There was not any significant difference between the Picture Writing $(\mathrm{M}=16.13)$ and Summary Writing $(\mathrm{M}=$ 16.43) groups on the posttest of writing accuracy $(\mathrm{MD}=.20, \rho=.923>.05)$. Thus, there is not any significant difference between the accuracy of Picture Writing and Summary Writing tasks. 
5: There was not any significant difference between the Picture Writing $(M=16.13)$ and Topic Writing $(M=15.93)$ groups on the posttest of writing accuracy $(\mathrm{MD}=.30, \rho=.781>.05)$. Thus, there is not any significant difference between the accuracy of Picture Writing and Topic Writing tasks.

6: There was not any significant difference between the Summary Writing $(\mathrm{M}=16.43)$ and Topic Writing $(\mathrm{M}=$ 15.93 ) groups on the posttest of writing accuracy $(\mathrm{MD}=.50, \rho=.394>.05)$. Thus, there is not any significant difference between the accuracy of Summary Writing and Topic Writing tasks.

TABLE 12

POST-HOC SCHEFFE'S TESTS; POSTTEST OF WRITING COMPLEXITY BY GROUPS

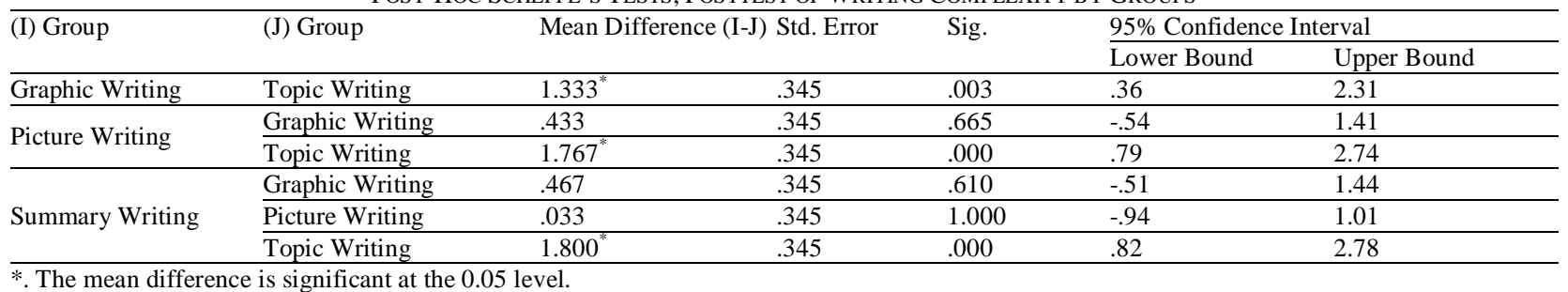

7: There was not any significant difference between the Graphic writing $(\mathrm{M}=16.10)$ and Picture Writing $(\mathrm{M}=16.53)$ groups on the posttest of writing complexity ( $\mathrm{MD}=.433, \rho=.665>.05)$. Thus, there is not any significant difference between the complexity of Graphic Writing and Picture Writing tasks.

8: There was not any significant difference between the Graphic Writing $(\mathrm{M}=16.10)$ and Summary Writing $(\mathrm{M}=$ 16.57) groups on the posttest of writing complexity $(\mathrm{MD}=.467, \mathrm{P}=.610>.05)$. Thus, there is not any significant difference between the complexity of Graphic Writing and Summary Writing tasks.

9: There was a significant difference between the Graphic Writing $(\mathrm{M}=16.10)$ and Topic Writing $(\mathrm{M}=14.77)$ groups on the posttest of writing complexity $(\mathrm{MD}=1.33, \boldsymbol{\rho}=.003<.05)$. Thus, there is significant difference between the complexity Graphic Writing and Topic Writing tasks.

10: There was not any significant difference between the Picture Writing $(\mathrm{M}=16.53)$ and Summary Writing $(\mathrm{M}=$ 16.57) groups on the posttest of writing complexity ( $\mathrm{MD}=.033, \boldsymbol{\rho}=1>.05)$. Thus, there is not any significant difference between the complexity of Picture Writing and Summary Writing tasks.

11: There was a significant difference between the Picture Writing $(\mathrm{M}=16.53)$ and Topic Writing $(\mathrm{M}=14.77)$ groups on the posttest of writing complexity (MD $=1.76, \rho=.000<.05)$. Thus, there is significant difference between the complexity of Picture Writing and Topic Writing tasks.

12: There was a significant difference between the Summary Writing $(\mathrm{M}=16.57)$ and Topic Writing $(\mathrm{M}=14.77)$ groups on the posttest of writing complexity (MD $=1.80, \rho=.000<.05)$. Thus, there is significant difference between the complexity of Summary Writing and Topic Writing tasks.

\section{Discussions AND CONCLUSIONS}

The motivation for the present study was the several hypotheses which were formulated regarding the effects of task activities on task performance of intermediate Iranian EFL learners. In the main, these hypotheses have received support, although in some cases these supports were limited in some cases.

Hence, the researcher drew the following conclusions from the findings of the study and theoretical propositions of the related literature:

The first and foremost conclusion is that task-based language teaching in an intermediate academic setting is not only possible but also effective. Students were taught and assessed following the implementation of four task-based language practices and when they were assessed at the end of the semester; their scores in the post test treatment in all four groups were higher than the scores in pretest treatment.

Task-based language teaching (TBLT) improves students' writing skill and develops students' attitudes towards English.

Further, the type of tasks did affect differently on the degree of the utility of them in developing writing performance.

The present study supports the findings of previous research regarding the unlike impacts of writing tasks on intermediate EFL learners writing performance (e.g., Birjandi \& Ahangari, 2009; Rezazadeh, Tavakoli, Eslami Rasekh, 2011; and $\mathrm{Xu}, 2009)$.

The treatment applied in this study produced positive results in students' performance on different writing groups' performance.

The most important contribution of this study is that it provides L2 learners and L2 educators with a clear explanation of how different kinds of writing tasks affect the L2 learners' writings performance.

Also, the researchers in this article propose that writing teachers should utilize task based approach to teach in a way to help students be more proficient in writing.

Analyzing findings of ANOVA indicates that students can be taught based on task oriented approaches to writing. Nevertheless, three limitations of this study should be considered. First, the study recruited students with intermediate 
English proficiency. The positive effects of the present study which have been demonstrated may not be generalizable to L2 learners with different proficiency levels due to the fact that L2 writers have varying commands of the target language. Second, to date, most task-based studies have focused on oral language production. This proposes that the repertoire of relevant studies to written material is poor. Third, writing compositions for an English speaking academic audience requires writing well at the sentence level, the paragraph level, and the organizational level. Some students were not writing because they had a problem in organizing ideas at this level.

\section{ACKNOWLEDGEMENT}

First of all, we thank God for giving us the strength and patience to carry out this paper and for giving us the chance to cooperate with many great people who have been our greatest support in doing this professional study.

We sincerely owe our gratitude to a number of people and institutes without whose help and contribution this paper would not have come to the present shape: To all those who during our involvement in accomplishing this paper, they have been steadfast in their support and have offered much valuable advice.

\section{REFERENCES}

[1] Birjandi, P., \& Ahangari, S. (2009). Effects of Task Repetition on the Fluency, Complexity and Accuracy of Iranian EFL Learners' Oral Discourse. The Asian EFL Journal, 10, 3, 28-52. 2008, September. ISSN 1738-1460. Retrieved April 12, 2013, from http://tinyurl.com/qese9zr.

[2] Chen, H., \& Wu, X. (2001). Effect of Task Type and Task Condition on EFL Writing Performance [D]. Doctoral thesis, Guangdong University of Foreign Studies. Retrieved January 2, 2013, from http://tinyurl.com/ouv7scc.

[3] Duddly - Eavens, T. \& St John, M. J. (2005). Developments in English for specific purposes. United Kingdom: CUP.

[4] Field, A. (2009). Discovering Statistics Using SPSS. ${ }^{\text {rd }}$ ed. London: SAGE.

[5] Fowler, W. S., \& Coe, N. (1976). Nelson English Language Tests. Great Britain: Butler \& Tanner Ltd.

[6] Magrath, C. P., Ackerman, A., Branch, T., \& Bristow, C. (2003). The National Commission on Writing in America's Schools and Colleges. The Neglected "R": The Need for a Writing Revolution. Retrieved March 27, 2013, from http://tinyurl.com/nxfs2by.

[7] Marashi, H., \& Dadari, L. (2012). The Impact of Using Task-based Writing on EFL Learners' Writing Performance and Creativity. Theory and Practice in Language Studies, 2, 12, 2500-2507. 2012, December. ISSN $1799-2591$. doi:10.4304/tpls.2.12.2500-2507. Retrieved March 18, 2013, from http://tinyurl.com/nwrr2px.

[8] Nunan, D. (2004). Task-Based Language Teaching. Cambridge: CUP.

[9] Pourdana, N., Karimi Behbahani, S. M., \& Safdari, M. (2010). The Impact of Task Types on Aspects of Iranian EFL Learners' Writing Performance: Accuracy, Fluency, and Complexity. IPEDR, 20, 261-265. 2011. Retrieved February 12, 2013, from http://www.ipedr.com/vol20/51-ICHSC2011-M10043.pdf.

[10] Rezazadeh, M., Tavakoli, M., \& Eslami Rasekh, A. (2011). The Role of Task Type in Foreign Language Written Production: Focusing on Fluency, Complexity, and Accuracy. International Education Studies, 4, 2, 169-176. 2011, May. doi:10.5539/ies.v4n2p169. Retrieved March 4, 2013, from http://tinyurl.com/knpffas.

[11] Samuda, V., \& Bygate, M. (2008). Tasks in second language learning. Great Britain: Antony Rowe Ltd, Chippenham and Eastbourne.

[12] Xu, J. (2009). An Experimental Study on the Effects of Different Reading Task on L2 Vocabulary Acquisition. 2, 3, 69-79. 2009, September. Retrieved June 23, 2013, from http://tinyurl.com/m3daag6.

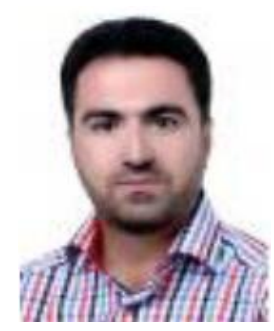

Abdolreza Abdali was born in Iran, Lorestan Province, Koohdasht in 1976. He has BA in English literature from Islamic Azad University, Boroujerd Branch, Lorestan Province, Iran in 2000. He was also graduated from MA degree in English language teaching from Faculty of Persian Literature and Foreign Languages, Islamic Azad University, Roudehen Branch, Tehran, Iran in 2013.

He was exempted from military services as he was recruited in Teacher Training Center. He has taught English for 20 years in high schools and universities.

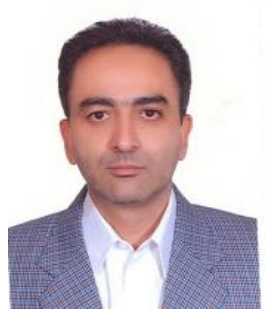

Hamidreza Fatemipour was born in 1966 in Mashhad, Khorasan Province, Iran. He graduated in English language teaching (Ph.D. degree) from Panjab University, Chandigarh, India in 2008.

$\mathrm{He}$ is an Assistant Professor in the Department of ELT, Islamic Azad University, Roudehen Branch, Roudehen, Iran. He has been the Dean of the Faculty of Persian Literature and Foreign Languages, IAU, Roudehen Branch since 2009. His research interests are CLIL, CALL, and Reflective Teaching. Dr. Fatemipour was one of the authors of the book, entitled "Read the Press". Tehran, Iran: Shokoh-e-Andisheh, 2005. He published three papers in different Journals and presented six papers in international conferences in Iran, Spain, Japan, and Belgium.

Dr. Fatemipour is a member of TELLSI, Teaching English Language and Literature Society of Iran. 